\title{
Technical analysis: the psychology of the market of dry bulk freight rates
}

\author{
Joan Mileski ${ }^{1}$, Christopher Clott $^{2}$, Cassia Bomer Galvao ${ }^{1 *}$ (D) and Taliese Laverne ${ }^{1}$
}

\author{
* Correspondence: galvaoc@tamug. \\ edu; cassiabgalvao@gmail.com \\ ${ }^{1}$ Texas A\&M University Galveston, \\ Galveston, USA \\ Full list of author information is \\ available at the end of the article
}

\begin{abstract}
Financial technical analysis of markets and trends differs from fundamental analysis in that econometrics are used on "fundamental" economic data in fundamental analysis. Technical analysis, however, adds to the overall trend analysis an additional examination of the psychology of markets. For freight rate predictions, there has been an exclusive reliance on typical fundamental analysis. Our results indicate that adding technical analysis to freight rate prediction can provide a better overall result. Psychological forces such as "irrational exuberance" or severe bearishness can influence trend predictions making them at best incomplete and at worst inaccurate for predicting the demand for shipping services. Further, ship construction decisions use freight rate predictions. In this paper, we perform a 20-year technical analysis of the BDI/Baltic Dry Index (formerly BFI/Baltic Freight Index) This analysis is a better, richer evaluation of freight rate trends that influence ship construction. Furthermore, technical analysis requires specific in-depth knowledge of the psychology of the market and experience in this type of trend analysis.
\end{abstract}

Keywords: Freight rate forecasting, Technical analysis, Baltic dry index, Psychological analysis

\section{Introduction}

In shipping cargo, the key to business success is accurate forecasting of market factors (Gharehgozli et al. 2018). Stopford (2009) also indicates that forecasting is not optional for success but it paves the way for all parties to earn a living. The ability to predict freight rates also allows decision-makers to better choices in the timing of fleet expansion and deployment. Furthermore, freight rates are an essential part of the business and financial planning of these stakeholders (Metaxas 1971) and affect several dynamics in the main four markets in shipping: owning; chartering, building, and scrapping (Stopford 2009).

As noted, freight rate forecasts are important to the main four markets and therefore, to shipyards developing efficient designs, to engineering companies estimating the demand for ship and port equipment, and to rating agencies calculating the risk of port and ship facility financing (Xu et al. 2011). Charterers also need reliable freight rate predictions as they represent customers of finished goods. Additionally, supply chain managers and freight forwarders can determine the best routes for their products with

(c) The Author(s). 2020 Open Access This article is licensed under a Creative Commons Attribution 4.0 International License, which permits use, sharing, adaptation, distribution and reproduction in any medium or format, as long as you give appropriate credit to the original author(s) and the source, provide a link to the Creative Commons licence, and indicate if changes were made. The images or other third party material in this article are included in the article's Creative Commons licence, unless indicated otherwise in a credit line to the material. If material is not included in the article's Creative Commons licence and your intended use is not permitted by statutory regulation or exceeds the permitted use, you will need to obtain permission directly from the copyright holder. To view a copy of this licence, visit http://creativecommons.org/licenses/by/4.0/. 
rate trend knowledge. Further, freight rate forecasts are extremely important because they are used not only by shippers and ship-owners to price cargo movements but also by banks to estimate earnings on the ships they mortgage.

The use of indices is a common practice among maritime sector members to better understand the system dynamics of the market and enable their decision process (Karamperidis et al. 2013). However, the investigation by FED - Federal Reserve Bank of Dallas (2010) indicates that the indices used in the dry bulk market tend to suffer from a mismatch of supply and demand mainly associated with the fleet long lifespan. Although econometric methods provide a good basis for freight rate prediction, they often miss the impact of market psychology. Whether "irrational exuberance" or severe bearishness exists in the market, inaccurate predictions for the demand for shipping services can occur. This inaccuracy in demand prediction can affect several levels of decision making in the ship construction and fleet deployment.

There are similar concerns for the forecasting of stock and bonds in the finance literature. Investments such as stock and bonds as well as pricing of certain commodities follow patterns. These patterns are often evaluated by the application of the fundamental economic theory of supply and demand. However, there is a psychological aspect to the pricing of investments and commodities that is beyond fundamental analysis referred to as the psychology of markets (Daniel et al. 2002).

This psychology of markets cannot be evaluated by traditional fundamental analysis but on what is called "technical analysis." Technical analysis can provide an understanding of psychological patterns and assist in the predictability of these patterns. It can provide forecasts of asset prices based on visual examination of the history of price movements (Edwards and Froot 1967). Certain quantitative summary measures of past price movements such as momentum indicators (oscillators) or moving averages may also be used (Murphy 1986).

Reliance on technical analysis is skewed towards shorter horizons (Taylor and Allen 1992). This is due to emotional reactions dissipating quickly in the market. Some consider it self-fulfilling (Malkiel 1981). Yet others feel that technical analysis contributes to overvaluation or the overshooting of the market (Frankel and Froot 1986, 1990) resulting in crashes (Shiller 1989).

However, there is a perceived complement of technical and fundamentalist analysis (Taylor and Allen 1992). Technical analysis is a broad class of prediction rules with unknown statistical properties, developed by practitioners with reference to any formalism (Neftci 1991). However, Wiener-Kolmogorov prediction theory, a fundamental methodology, should better forecast stochastic processes, yet market traders use technical analysis in the day-to-day forecasting successfully although it bears no direct relationship to the Wiener-Kolmogorov prediction theory (Neftci 1991).

Technical analysis has long been a pervasive activity in other markets such as security and futures markets (Blume et al. 1994). Further, technical analysis arises as a natural component of the analysts' learning process. Cycle analysis is used in optimization problems and market cycles by identifying extremes in investor psychology, highs, and lows in prices, and other collective factors. The principle of cycle analysis assumes that market prices unfold in specific patterns and rhythmical procedures (Blume et al. 1994). This ability to identify extremes may assist with capacity decisions because freight rate predictions are more accurate and timely. 
Enhancing the effectiveness and efficiency of freight rate planning is a critical component in managing the total supply chain. Technical analysis can give a more robust analysis of freight rates when complemented by fundamental analysis. Fundamental econometric methods such as Fuzzy Times Series forecasting predict freight rates well (Duru 2010). However, the use of both fundamental and technical methods of data analysis, with an eye to the "why" of changes in the direction of freight rates, can enhance the decision-making process of fleet expansion as well as merely predicting freight rates as capacity decisions are often a reaction to freight rate trends.

This paper uses technical analytics to evaluate freight rate trend prediction. We contend that similar to other investments and commodity pricing, freight rates follow predictable patterns based on both fundamental and psychological trends. These trends can assist in supply chain and fleet management (Trkman et al. 2010). We further contend that the use of this analysis can show how capacity "overshoots" the market freight rates creating cyclical overcapacity. We apply technical analysis techniques to the Baltic Freight Index for 1996 through 2016, as it is still the main index used by industry practitioners (FED - Federal Reserve Bank of Dallas 2010). We then compare the trends and cycles to ships ordered. We find that orders continue to rise well after the turning point of freight rates declines confirming that investors overlook the psychology aspects of freight rate movements.

This paper is organized as follows: Section 2 addresses the technical analysis and the psychology of freight rates. Section 3 discusses the methodology to test the contention that whether market freight rates affect fleet capacity. Section 4 evaluates the results of the trends discovered. Section 5 further discusses the findings. Section 6 concludes the implications for managers.

\section{Technical analysis and the psychology of freight rates literature review}

The operational strategies of shipping companies including fleet-level decisions are impacted by freight rates (Charemza and Gronicki 1981). Since the lead-time to construct a cargo ship can exceed one or more years, forecasting freight rates accurately can better predict the level of needed ship construction. Predicting the operational decision whether to add to the fleet is generally in the hands of company financial decisionmakers. These financial decision-makers have the talent to forecast. They generally rely on typical fundamental econometric analysis to predict trends. Many have applied these techniques to freight rates (Cullinane et al. 1999; Chen et al. 2012; Chung and Weon 2013; Zeng et al. 2016).

There is generally a reliance on typical econometric methods including econometric modeling, simultaneous equations models, and time-series analysis methods to predict freight rate trends (Tinbergen 1959; Shimojo 1979; Charemza and Gronicki 1981; Hampton 1991; Hale and Vanags 1992; Cullinane 1992; Beenstock and Vergottis 1993; Glen 1997; Kavussanos 1996, 1997). Other econometric methods include moving averages, autoregression, and smoothing methods (Holt 1957; Winters 1960; Box and Jenkins 1976; Bowerman and O'Connell 1979; Harvey 1990), judgmental forecasting (Sanders 1992; Goodwin and Wright 1993), and Delphi-based and expert opinionbased methods (Ariel 1989; Duru and Yoshida 2008a, 2008b, 2009). Many of these methods and models rely on various assumptions of the user. 
Alternative approaches who have considered judgmental forecasting in addition to statistics models or used time-varying coefficient models have used these methods in comparing the Baltic Dry Bulk Index (BDI) (Duru and Yoshida 2009, 2011; Ko 2013). These studies have concluded that expectation formation in the shipping market is not well incorporated into present BDI.

Recent studies have tried to incorporate novel approaches to forecasting bulk freight rates. Angelopoulos (2017) has used the dynamic spectral content of the BDI to discuss its cyclical behavior through time-frequency analysis; and Tsioumas et al. (2017) have integrated the Dry Bulk Economic Climate Index (DBECI) into a VARX model to improve the accuracy of BDI forecasts. Although these methods provide a good basis for freight rate prediction, they often miss the psychology of the market impact on the rates.

Fundamental analysis relies on variables on the overall economy to predict market trends. Certain variables are leading indicators of what the economy will do and other variables are lagging indicators describing what has already occurred. Business analytics or analysis of these variables has helped businesses make better decisions and improve performance (Trkman et al. 2010). How and where to best use analytics is evolving. There is evidence that business analytics may be useful in the maritime industry through supply chain decisions (Trkman et al. 2010). The concern with this type of analysis is whether the forecasting models and trends have sufficient parameters in the design to be accurate. Therefore, much of the process of prediction involves trial and error (Kaastra and Boyd 1996).

In analyzing the psychology of a market, a different approach is taken. We assume that certain information that affects the pricing of commodities is not immediate and is not yet incorporated into the current market price (Blume et al. 1994). Psychological trends often take the shape of cycle or "waves." These cycles are perceived to have a rhythm. These cycles are similar to physical processes, such as tides (Roberts 1959). Sometimes the trends have momentum that eventually regresses to a mean in the market. Similarly, the momentum indicator is developed through the moving average of a variable (Daniel et al. 1998).

Further, understanding the history of a market is important to the predictability of trends (Roberts 1959). Therefore, there is an element of subjective judgment in the application of psychological analysis (not unlike judgmental forecasting) but it must be put in the context of history and current circumstances. Some believe that chance behavior in markets itself produces "patterns" that invite spurious interpretations (Roberts 1959). However, there is good empirical evidence that technical analysis improves performance significantly (Neely et al. 1997) although technical analysis has been long regarded by academics with a mixture of suspicion and contempt (Neely et al. 1997). Malkiel (1981) describes Technical analysis as the anathema to the academic world.

The efficient market hypothesis is also under siege, as it cannot explain all variations in price (Brock et al. 1992). Again, studies do show that technical analysis helps to predict price changes in markets. The patterns uncovered by technical rules cannot be explained by traditional statistical analysis such as autocorrelation, random walk, etc. (Brock et al. 1992).

The psychological trends are dependent on the types of information investors and traders receive on the market. For example, if the information on the aggregate supply 
of a commodity is poor, different investors may take different actions (Blume et al. 1994). Further, the amount of information whether on economic trends or political events influences the psychological assessment of the market trend. Therefore, asymmetry in information may play a role but there may be other causes such as market inefficiency and differing market expectations or expectation errors by investors (Neely et al. 1997). However, most importantly, it is the knowledge and experience of the analyst of the market that makes the most difference to correctly seeing psychological trends (Blume et al. 1994). Again, these types of analysts are referred to as technical analysts. Pring (1980) contends that technical analysis is built on price movements, which are a reflection of mass psychology (fear, panic, confidence, etc. all encompassed). As such, technical analysis is often viewed as an art rather than the application of social science to econometrics. When well-executed it can help to identify forces and predict the peaks and bottoms of a given market. Pring (1991) further elaborates that the way information is framed and presented it makes an impact on the rational choice. As such, technical analysts usually examine the uncertainties of markets in the psychological context.

The psychology of markets often views investors in three categories: smart money, average money, and dumb money (Frazzini and Lamont 2008; Akbas et al. 2015). Smart money enters a particular market early when the market trend is going in the right direction. Smart money also exits before the "bubble" bursts meaning the smart money leaves a particular market before the trend reverses. Average money enters a particular market later than smart money but as the market is still ascending. Average money may or may not leave before the "bubble" bursts. Dumb money enters the market much later than smart or average money. It wants to get into the market where everyone is making money. The problem with dumb money is that it stays too long and generally creates the "bubble." Dumb money contributes to overcapacity in a market overshooting the needs of operations. Another way to put this phenomenon is that smart money gets out earlier because of the principle of diminishing sensitivity where investors value incremental gains more than riskier gains (Tversky and Kahneman 1992).

In the psychology of shipping freight rates, research has identified waves and cycles. Using these waves and cycles, practical forecasting of turning points in freight rates and the "sentiment" in the shipping market is 1-4 years ahead of time. Turning points refers to signals of major market downturns and upturns.

Another study shows that one-year time charter weekly freight rates are highly volatile and predictable only under nonlinear low dimensional chaos (Goulielmos and Psifia 2009). Zeng et al. (2016) report that the empirical mode decomposition method does provide a useful technique for dry market analysis and forecasting, thus, showing that natural signals can be used. Ndikom (2006) indicates that forecasting freight rates should be based on the principles of planning, which usually uses past and present variables to postulate future extrapolation of rates. Finally, maritime technical analysis supports long term cycles of 16 to 24 years and short-term cycles of 3 to 4 years (Goulielmos 2012).

Forecasting freight rates are not fully predictive by using traditional econometric models (Manzanero and Krupp (2009). Duru et al. (2012) use the fuzzy DELPHI adjustment process for improvement in accuracy for freight rate prediction. Part of the inaccuracy attributed to typical econometric methods is that the methods require several 
assumptions about the data including the normality and independence that often are not met (Goulielmos and Psifia 2009, 2011).

Therefore, it appears that technical analysis is and can be a good tool to predict freight rates. The question remains whether reliable freight rate prediction assists in better ship capacity needs. Randers and Goluke (2007) identify a 20-year wave based on capacity adjustments and a 4-year cycle based on capacity utilization. Second-hand tanker ship markets also are found to have cycles (Goulielmos and Siropoulou 2006).

In this paper, technical analysis shows that freight rate market predictions can help the capacity needs decisions and technical analysis with fundamental analysis can predict rates more fully. Further, technical analysis can help reduce overcapacity by identifying the value of freight rates where the market signals a turning point. Again, the turning points refer to signals of major market downturns and upturns according to the moving average method of technical analysis.

Therefore, we hypothesize that technical analysis can show when to reduce capacity needs (number of ships) of the operations to not overshoot the market due to the psychological reaction to freight rates. We further contend that technical analysis can achieve this by identifying the market signals that a turning point has occurred.

\section{Methodology}

We apply basic technical tools to freight rates for the years 1996 to 2016 to analyze patterns. We recognize that there are many fundamental analysis methods to predict freight rates; however, this analysis focuses on pattern identification due to the psychology of the market through technical analysis methods. We look at when the market turns direction and identify the consequence of continuing to make decisions on a trajectory before the turn; thus, "overshooting" the market.

We use the Baltic Dry Freight Index (BDI) as a source of our data. Created in 1985, BFI (Baltic Freight Index) became BDI in 1999 (Baltic Exchange 2017). ${ }^{1}$ These data are obtained from the monthly reports in Clarkson's Database (Clarkson 2017). Due to its reliability, we use monthly data provided by Clarkson Shipping Intelligence Network Time Series for the years 1996 to 2016. The BDI Index in Clarkson (2017) considers Jan 04th in $1985=1000$ (Baltic Exchange). ${ }^{2}$

Because dry bulk primarily consists of materials that function as raw material inputs to the production of intermediate or finished goods, the index is also seen as an efficient economic indicator of future economic growth and production (Port News 2017). Some fundamental analysts have tried to use the BDI as a lagging indicator of world GDP. We match the BDI data with the data on the general cargo ships of total deadweight tonnage (DWT) also provided by Clarkson's monthly for the years 1996 to 2016. Further, additional data for the general cargo DWT categorized by ship size (i.e.

\footnotetext{
${ }^{1}$ According to The Economic Times (2017): "A Panamax vessel is a vessel that is capable of navigating through the Panama Canal and has a 50,000-80,000 tonnage, while Capesize vessel means the vessel can navigate through the Cape of Good Hope and carries 100,000-130,000 tonnage. BFI is more relevant for bigger ships (...)"

${ }^{2}$ The Baltic Dry Index (BDI) is the successor to the Baltic Freight Index (BFI) and came into operation on 1 November 1999. Since 1 July 2009, the index has been a composite of the Dry Bulk Timecharter Averages. The following formula is used to calculate the BDI: ((Capesize5TCavg + PanamaxTCavg + SupramaxTCavg + HandysizeTCavg)/ 4) *0.10907849. The TCavg = Time charter average" (Baltic Exchange 2017). As per Baltic Exchange (2020), the current BFI formula reads as follows: ((Capesize 2014. TCavg * $0.4+$ PanamaxTCavg *0.3 + Supramax10TCavg "0.3) *0.1).
} 
total DWT of all ships ordered in the 5000-7499 DWT, 7500 - 9999, 10,000 - 14,999, $15,000-19,999$, and 20,000+), total sales (newbuilds and second-hand ships) of general cargo ships (DWT), and demolition of general cargo ships total DWT are collected.

Finally, we incorporate the yearly reported World Gross Domestic Product (GDP). World GDP data is collected from World Bank (2017) and the data for BDI, ships ordered by DWT, ships ordered by ship size, total ship sales, and demolition of ship data are all obtained from Clarkson's Shipping Research Services (Clarkson 2017).

We use a moving average methodology as described by Brock et al. (1992) to test that technical analysis identifies the psychology or the reaction to freight rates and shows that the capacity needs (number of ships) of the operations overshoot the market demands. We further contend that technical analysis can help reduce overcapacity by identifying the timing of a turning point in the market. Again, the turning points refer to major market downturns and upturns according to the moving average method of technical analysis. This method is the simplest and most popular with traders (Neftci 1991). Further, the tools of the technical analyst include charts and trend plotting (Taylor and Allen 1992). Chart and plotting visually identify turning points.

According to the moving average rule (see Eq. 1 below), buy and sell signals are generated by two moving averages - a long period average addressing long trends in the world market and a short period average addressing short-term moves in freight rates (Brock et al. 1992). We calculate the long period average using the world GDP. We calculate the short period average using the BDI. Using two data sets for long and short average calculations is common in technical analysis. When the short period moving average penetrates the long period average, a trend is considered initiated. We use correlation computations to isolate the fundamental patterns from psychological aspects using each variable.

$$
\text { Moving average }=\frac{\sum B D I \text { or GDP during the past } n \text { periods }}{n}
$$

We plot the BDI moving average over time to analyze the trends and identify the turning points. We also plot World GDO for the same period of time as well as general cargo ships ordered by size class, and BDI moving average versus total DWT of general cargo ships demolished. The results of these data plots give insight into the relationship between the BDI and general cargo ship orders. Further, they can lead future predictions to decrease the overcapacities seen in the maritime industry.

The BDI moving average is calculated on a two-month basis from the data from January 1996 - December 2016 as follows: Add January 1996 data and February 1996 data then dividing by two $\left(\frac{980+974}{2}\right)$. This process is repeated with February and March, and then March and April, etc. until the moving average is created for the entire set. All correlations between all data sets (GDP, ship data, etc.) are completed in excel where the data analysis package contains a correlation program. The correlations between each variable list above are calculated on full data sets from January 1996 to December 2016.

Finally, the data are plotted (graphs) and visually show relationships between variables. The BDI moving average, general cargo ships total DWT ordered, and World GDP are graphed separately on the same timeline.to avoid scaling issues and to see the variation and changes in the BDI and ships' orders when compared to World GDP. 
Next, the different sizes of ships ordered by DWT over the past 20 years are plotted on one graph. Lastly, the demolition of general cargo ships is plotted against the BDI moving average.

\section{Results}

Our results provide strong support for the benefits of using technical analysis. Further, our results have predictive power for trend analysis. The correlations of the data sets show interesting results below.

There are correlations between the BDI moving average and general cargo DWT ordered; total sales; and World GDP (Table 1). BDI moving average and General Cargo DWT ordered show a correlation of $61.41 \%$. This represents that almost $62 \%$ of the time general cargo ships are ordered based on the BDI. General cargo DWT ordered and World GDP show a correlation of 42.91\% and total sales and World GDP has a relationship of $40.58 \%$ (listed as Global GDP in Table 1). While the total sales of a general cargo ship (total DWT) and the BDI moving average do show a positive relationship it is only $20 \%$. Table 1 shows the correlations of each of the data sets to all other data sets. The most significant findings are highlighted.

Comparing the graphs of the BDI (Fig. 1), General Cargo ordered total DWT (Fig. 2), and World GDP (Fig. 3) are all on the same timeline for comparisons. First looking at Figs. 1 and 2 a similar shape appears. Upon further inspection, you can see that Fig. 2 has a slight delay cargo response to the BDI turning point of roughly a year. The BDI shows a turning point between January 2007 and January 2008 and another turning point shortly after January 2008, while the general cargo ordered has a turning point shortly after January 2008. When overlaying World GDP (Fig. 3) with Figs. 1 and 2 there is a constant slope upwards with a slight peak in 2010 followed by a minor fall in 2011 with a recovery in 2012.

Looking at the comparison of the ship sizes ordered in Fig. 4 the mix of ships is changing - the larger ship sizes falling and the smaller ship sizes rising in response to the BDI turning point. This does show a reduction in overall capacity because of freight rates dropping. However, the delay of over 2 years in the total number of ships ordered shows the "overshooting" of the market for ships rather than responding to the turning point immediately. This confirms our contention that freight rate prediction via technical analysis if responded to appropriately, may better predict when to order expansions to the fleet.

Finally, looking at the graph showing the BDI and the total DWT demolished shows when the BDI spikes at an upward turning point the demolition of ships slows or flat lines and when the BDI troughs the demolitions increase. However, again the demolitions lag by at least a year for the upward turning point. This again confirms that technical analysis may assist in predicting the timing of freight rate cycles. Again, technical analysis best predicts the short-term periods. As indicated by GDP the long-term market is consistently upward.

\section{Discussion of findings}

The technical analysis of charting data and calculating moving averages shows the cycles and turning points create a puzzle of market events that fit together nicely. The first pieces are Figs. 1 and 2. The BDI and total general cargo ordered show a 


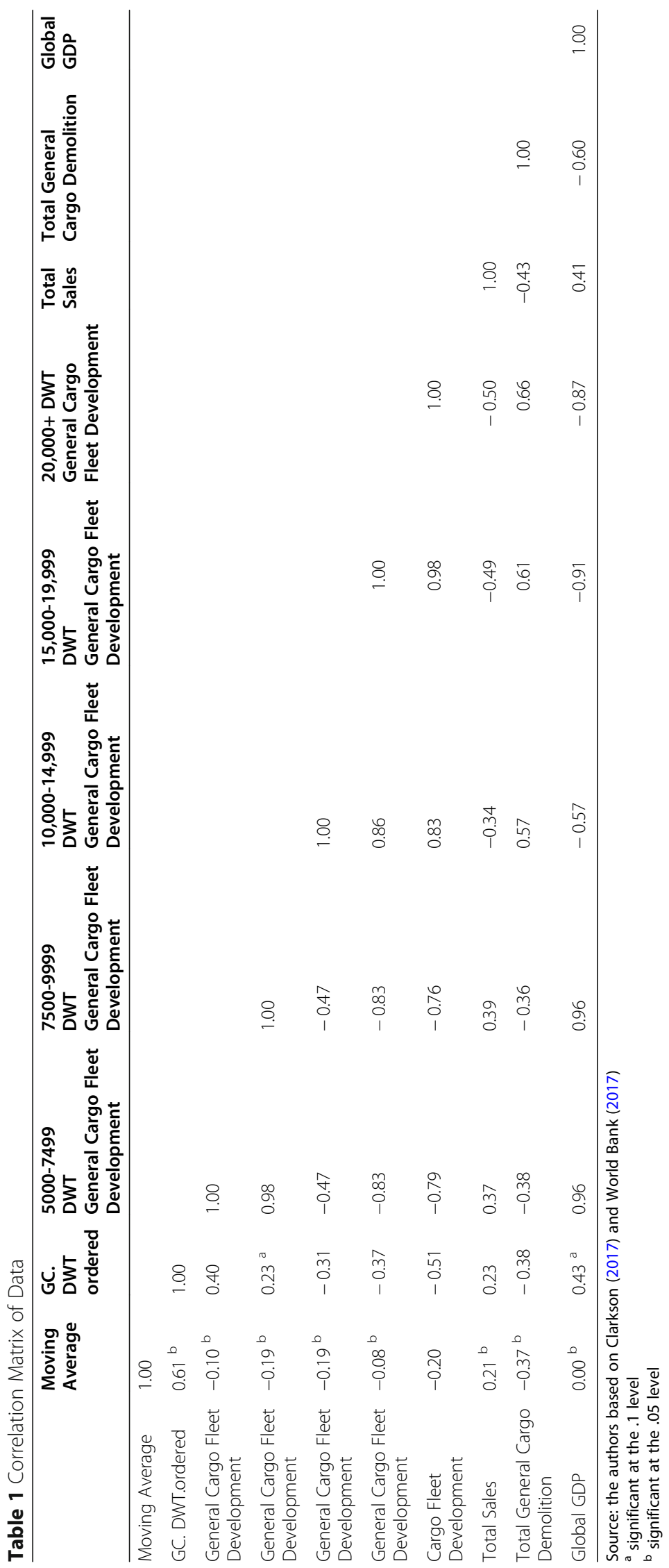




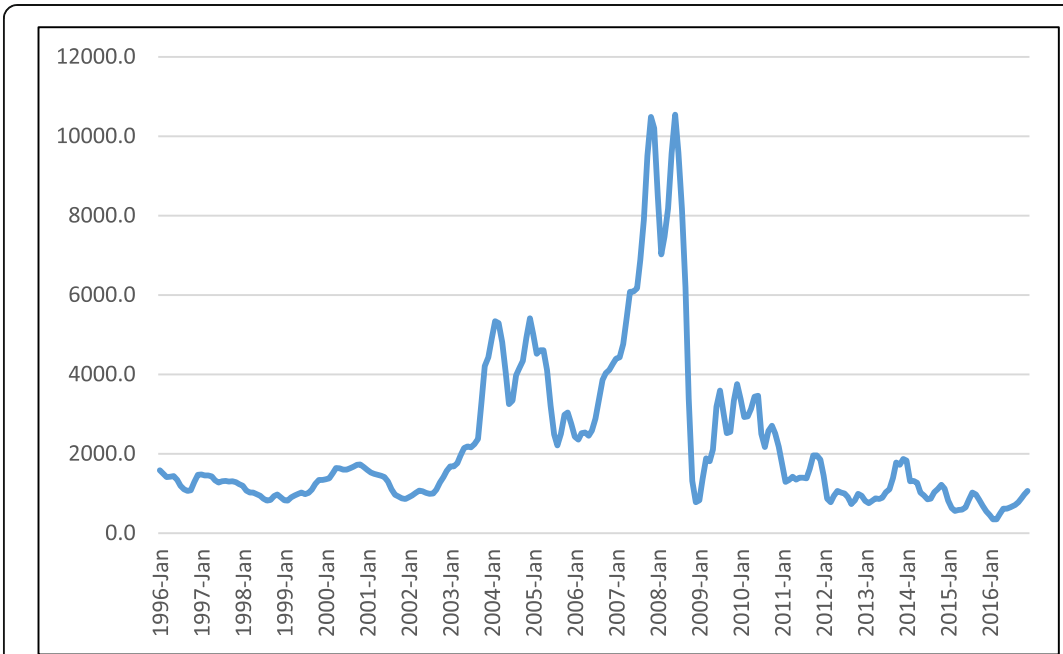

* The BDI accounts only the ships carrying DRY CARGO (oil, gas, chemicals or containers are not included) Source: the authors based on Clarkson (2017).

Fig. 1 The Baltic Exchange Dry Index* Moving Average. * The BDI accounts only the ships carrying DRY CARGO (oil, gas, chemicals or containers are not included). Source: the authors based on Clarkson (2017)

correlation as well as the graphs presented. However, there is a slight delay in the reverse of general cargo ordered after the BDI moving average peaks. Thus, this confirms that investors reacting slowly to the BDI in their decisions to order and build vessels. The correlation of the BDI and the amount ordered does suggest that investors react to shorter-term cycles as opposed to the World GDP or other indexes to invest in building new ships. As seen in the graphs above there is an overall increasing trend for World GDP. If investors used GDP as an index to base investment decisions, there would be a constant growth of ships ordered. Reality shows ship orders increase over 7 years' cycle followed by a major decline.

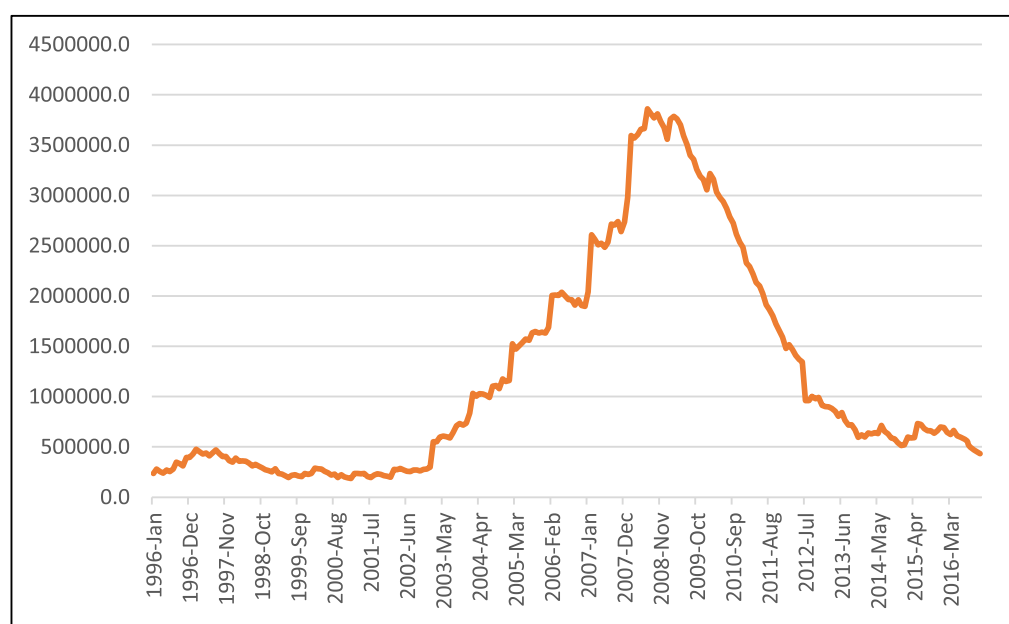

* The DWT here accounts only the ships carrying DRY CARGO (oil, gas, chemicals or containers are not included)

Source: the authors based on Clarkson (2017).

Fig. 2 General Cargo Ordered (total DWT*). * The DWT here accounts only the ships carrying DRY CARGO (oil, gas, chemicals or containers are not included). Source: the authors based on Clarkson (2017) 


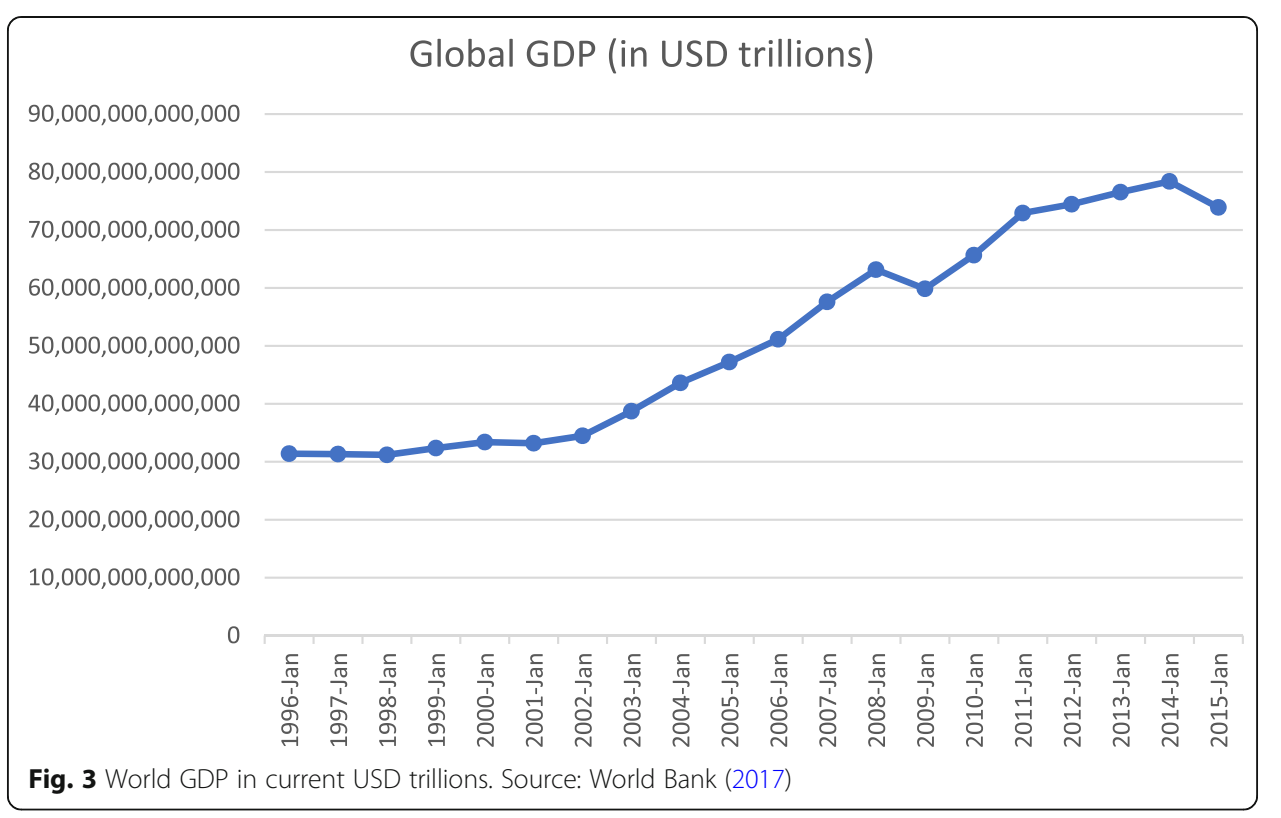

Another interesting factor is how the different sizes of ships fit into this puzzle. As mentioned in the results, smaller ship sizes are being ordered more than the larger ships. This is believed to create a reduction in the fleet (meaning, a small number of bigger ships covering the same tonnage), but allow the flexibility for market changes with smaller ships.

Further, external long-term forces may play into this strategy as seen by the longterm trend and cycles shown by the world GDP. Many ports are still in the process of expanding their capabilities to receive larger ships or simply are not able to expand. Smaller ships offer a wider range of ports available to receive them. This is counter to the fundamental economics of the shipping market that urges economies of scale. It

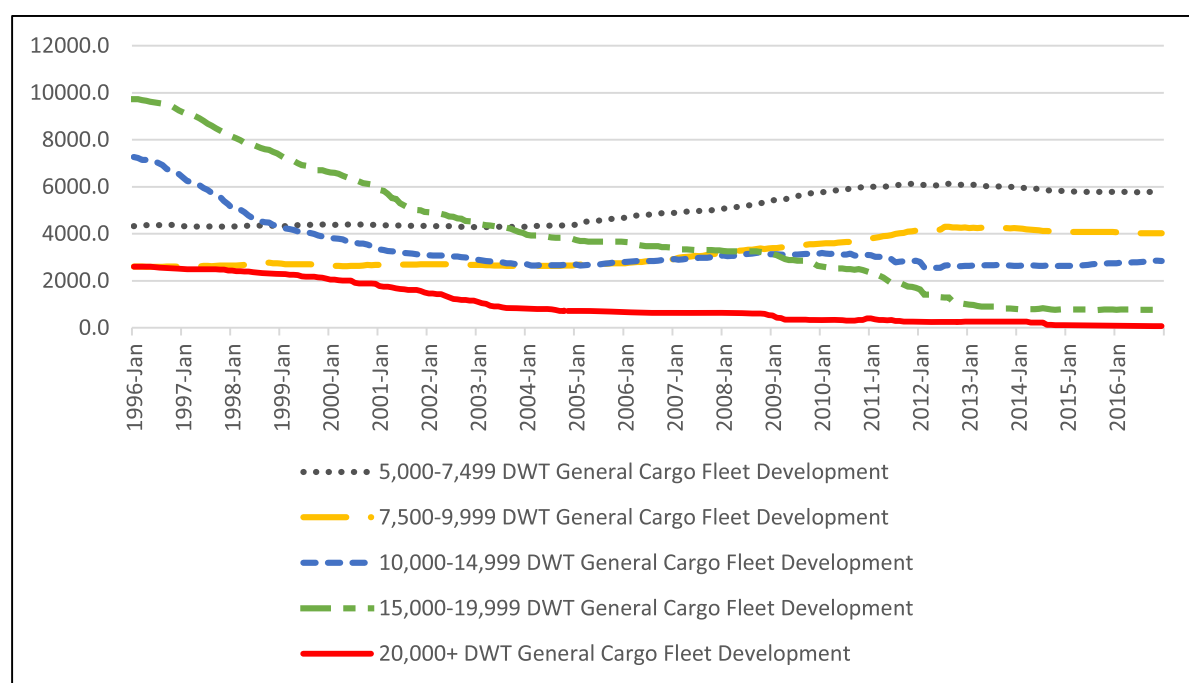

Source: the authors based on Clarkson (2017).

Fig. 4 Number of General Cargo Ships ordered by size class. Source: the authors based on Clarkson (2017) 
simply may mean that larger ships are not capable to call on every port. Often, investors are looking to move their own product(s) to destinations that cannot be reached by ships larger than 15,000 DWT. Thus, building a ship suitable to the receiving destination will be of more value.

Lastly is the BDI and the demolition of ships, and their importance to finishing the puzzle. Through our technical analysis, we have shown that the maritime shipbuilding market is cyclical. Using this tool of technical analysis can help predict the market trends potentially avoiding overshooting or overloading the shipping market capacity. This overcapacity can cause a rise in the number and capacity of ships that lags the real demand and as such, dropping freight rates. This mismatching also causes the demolition of ships to occur in response to a short-term cycle of freight rates rather than responding to the actual useful life of the ship. When there are too many ships on the market and not enough work for them, demolition of ships begins. Soon after demolition occurs, a shortage of ships generally follows repeating the cycle. The findings in the results of this technical analysis show that the BDI and the demolition of ships are negatively correlated and the demolition of ships responds to the short-term cycle. The highest amount of demolition occurs when the BDI is low. As seen in Fig. 5, the graph corresponds to the data. This result confirms our contention that technical analysis and the focus on cycles can help investors avoid falling into the trap of overshooting investment in ships and then panicking with the demolition of ships to reduce capacity.

\section{Concluding remarks}

Although fundamental analysis and standard econometric modeling do a good job of freight rate prediction, the findings indicate that technical analysis may better predict cyclical patterns in freight rates that may be missed by standard fundamental analysis. These

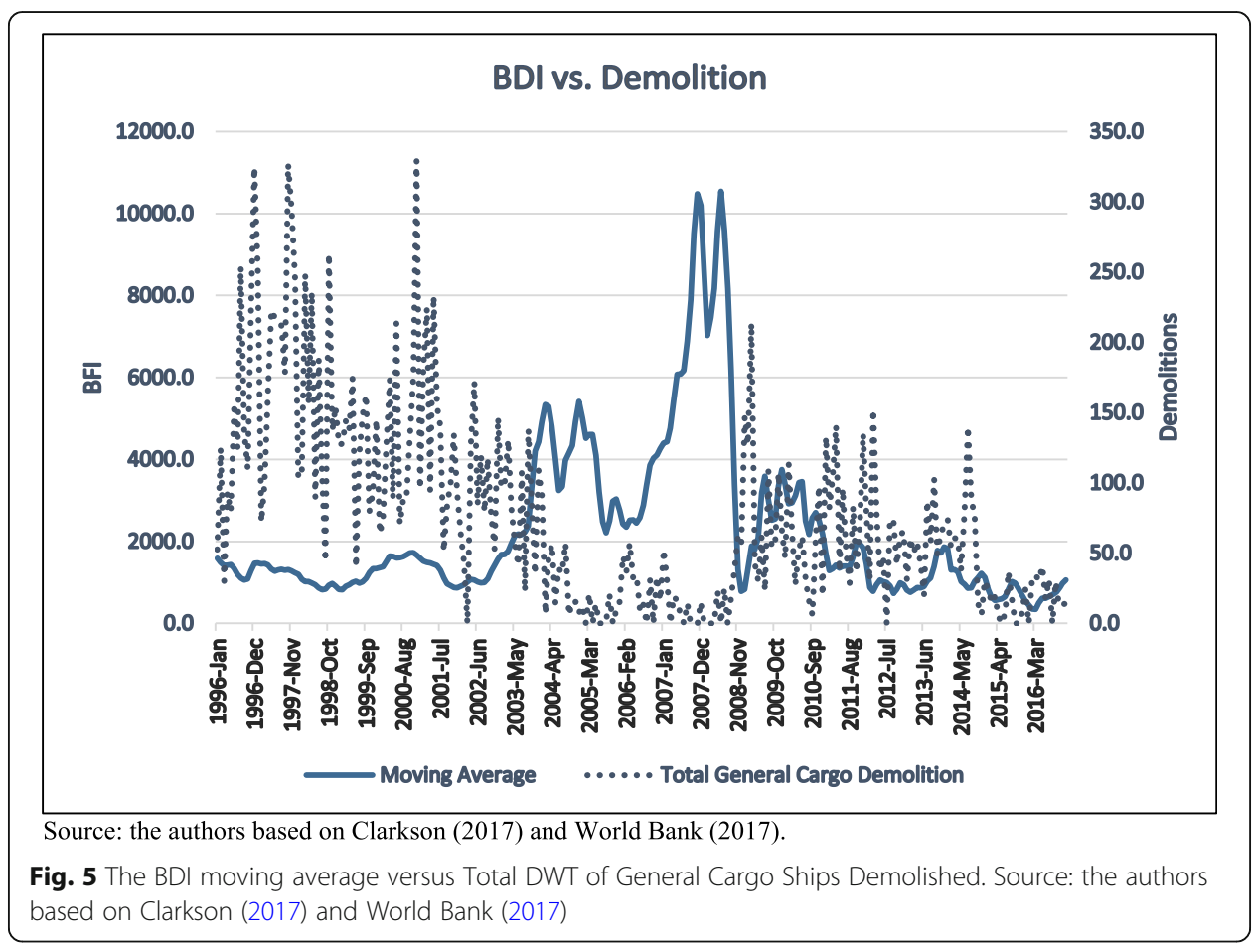


patterns may be useful to predict future rates. This potential predictability may lead to better timing of ship investment Further, better predictability enhances fleet development and technology adoption and usage. Better planning of supply chains may also result.

This paper finds that BDI and cargo orders are correlated, showing that investors can use the BDI to make investment decisions. However, BDI may be a good indicator of short-term cycles only. And that is because the BDI may show high levels of volatility considering the various types of tonnage considered in the index (the supply of large carriers tends to be small with long lead times and high production costs). Using more advanced technical and business analytics can enhance the knowledge of cycles. This advanced analysis may further address the problem of overbuilding in the shipping market. By showing investors that basing their decisions purely on the short-term BDI trends, overshooting and overloading the market may be reduced, resulting in less excess ship capacity and reducing the need for premature ship demolition.

Important to say that this research has not considered other influences impacting the dry bulk markets, such as seasonality or the specificities of the different vessel sizes (Capesize, Panamax and Supramax and Handymax). These factors are considered outside the scope of our analysis and provide an opportunity for future research.

Investors and managers may ask themselves whether technical analysis better manages the fleet capacity. Our results indicated that fundamental analysis can predict shipping markets well; however, technical analysis may add more to the discussion of short term reaction to market psychology. Market psychology can lead to poor timing of investment such as overshooting the market, and in the case of ship investment, overcapacity of supply. Thus, technical analysis research can also predict cycles of freight rates well.

Methods such as Fuzzy Time Series forecasting can greatly assist in the prediction of freight rates to ease the major spikes and depressions seen in the market. However, a wellexecuted technical analysis, like any art, requires fundamentals knowledge and practical experience. Such an analysis should be done by knowledgeable and experienced analysts.

Abbreviations

BDI: Baltic Dry Bulk Index; BFI: Baltic Freight Index; DBECl: Dry Bulk Economic Climate Index (DBECI); DWT: Deadweight tonnage; GDP: Gross Domestic Product; VARX: Autoregressive model

\section{Acknowledgements}

The authors would like to thank the anonymous reviewers for the valuable comments and suggestions that improved the paper quality and clarity. The authors take full responsibility for the paper argument integrity.

\section{Authors' contributions}

This research was a multiple hands project with all the authors getting engaged and dedicated. Here is the summary of authors specific contributions. Dr. Mileski was responsible for the conceptualization; research design and methodology. Dr. Clott and Dr. Galvao contributed with their industry background, as they both worked for 10+ years for the shipping industry prior their current roles in academia. Dr. Galvao also worked on the data collection and organization with Mrs. Laverne, as she was a student by the time the paper was first concluded. All authors contributed significantly for the analysis and Dr. Mileski did the final touch in the conclusions and language check, as a native English speaker. The author(s) read and approved the final manuscript.

Funding

no additional funding. Authors and their research efforts in this project were paid by their respective schools/ departments.

Availability of data and materials

all data used on the paper is made available in the manuscript. 
Author details

${ }^{1}$ Texas A\&M University Galveston, Galveston, USA. ${ }^{2}$ State University of New York, Clayton, USA.

Received: 30 August 2019 Accepted: 27 October 2020

Published online: 03 December 2020

\section{References}

Akbas F, Armstrong WJ, Sorescu S, Subrahmanyam A (2015) Smart money, dumb money, and capital market anomalies. J Financ Econ 118(2):355-382

Angelopoulos J (2017) Time-frequency analysis of the Baltic dry index. Marit Econ Logistics 19(2):211-233

Ariel A (1989) Delphi forecast of the dry bulk shipping industry in the year 2000. Marit Policy Manage 16:305-336

Baltic Exchange (2017). The Baltic Exchange Dry Index. Retrieved from http://www.balticexchange.com/market-information/ indices/BDI/. March, 2017

Baltic Exchange (2020). Guide to market benchmarks. Available at https://www.balticexchange.com/dyn/_assets/_forms/ guide-to-market-benchmarks.shtml

Beenstock M, Vergottis A (1993) Econometric modeling of world shipping. Chapman and Hall, London

Blume L, Easley D, O'Hara M (1994) Market statistics and technical analysis: the role of volume. J Financ 49(1):153-181

Bowerman BL, O'Connell RT (1979) Time series and forecasting: an applied approach. Duxbury Press, New York

Box GEP, Jenkins GM (1976) Time series analysis: forecasting and control. Revised edition. Holden-Day, Oakland

Brock W, Lakonishok J, Lebaron B (1992) Simple technical trading rules and the stochastic properties of stock returns. J Financ 47(5):1731-1764

Charemza W. Gronicki M (1981) An econometric model of world shipping and shipbuilding. Marit Policy Manag 8(1):21-30

Chen S, Meersman H, Van de Voorde E (2012) Forecasting spot rates at main routes in the dry bulk market. Marit Econ Logistics 14(4):498-537

Chung SK, Weon JH (2013) Long memory and asymmetric time varying spillover effects in dry bulk freight markets. Marit Econ Logistics 15(4):494-522

Clarkson (2017). Clarkson Research Database, Baltic Freight Index, General Cargo Ships Ordered By Total Deadweight Tonnage, Total General Cargo Ship Sales, and Total General Cargo Ship Demolition (Research Database), Date of Access: 24 Jan 2017. http://www.Clarksons.com

Cullinane KPB (1992) A short-term adaptive forecasting model for Biffex speculation: a Box_Jenkins approach. Marit Policy Manag 19:91-114

Cullinane KPB, Mason K, Cape M (1999) A comparison of models for forecasting the Baltic freight index: Box-Jenkins revisited. Int J Marit Econ 1(2):15-39

Daniel K, Hirshleifer D, Subrahmanyam A (1998) Investor psychology and security market under-and overreactions. The. J Financ 53(6):1839-1885

Daniel K, Hirshleifer D, Teoh SH (2002) Investor psychology in capital markets: evidence and policy implications. J Monet Econ 49(1):139-209

Duru O (2010) A fuzzy integrated logical forecasting model for dry bulk shipping index forecasting: an improved fuzzy time series approach. Expert Syst Appl 37(7):5372-5380

Duru O, Bulut E, Yoshida S (2012) A fuzzy extended DELPHI method for adjustment of statistical time series prediction: an empirical study on dry bulk freight market case. Expert Syst Appl 39(1):840-848

Duru O, Yoshida S (2008a) Composite forecast: a new approach for forecasting shipping markets. In: Proceedings for the International Association of Maritime Economists Conference, Dalian

Duru O, Yoshida S (2008b) Market psychology. Lloyd's Shipping Economist 30:30-31

Duru O, Yoshida S (2009) Judgmental forecasting in the dry bulk shipping business: statistical vs. judgmental approach. Asian J Shipping Logistics 25(2):189-217

Duru O, Yoshida S (2011) Long term freight market index and inferences. Asian J Shipping Logistics 27(3):405-421

Edwards JA, Froot KA (1967) Technical analysis of stock trends. John Magee, Boston

FED - Federal Reserve Bank of Dallas (2010). Globalization and Monetary Policy Institute 2010 Annual Report. Available at https://www.dallasfed.org/ /media/documents/institute/annual/2010/annual10e.pdf.

Frankel J, Froot KA (1986) Understanding the US Dollar in the eighties: the expectations of chartists and fundamentalists. Econ Rec 62(1):24-38.

Frankel, J., and Froot, K.A. (1990). Chartists, fundamentalists, and the demand for dollars. Private Behavior and Government Policy in Interdependent Economies

Frazzini A, Lamont OA (2008) Dumb money: mutual fund flows and the cross-section of stock returns. J Financ Econ 88(2): 299-322

Gharehgozli A, Duru O, Bulut E (2018) Input data range optimization for freight rate forecasting using the rolling window testing procedure. Int J Transport Econ 45(3):393-413

Glen DR (1997) The market for second-hand ships: further results on efficiency using cointegration analysis. Marit Policy Manag 24:245-260

Goodwin P, Wright G (1993) Improving judgmental time series forecasting: a review of the guidance provided by research. Int J Forecast 9:147-161

Goulielmos AM (2012) Long-term forecasting of BFI using Chaos cycle theory and maritime technical analysis. World Adv Res J Soc Sci 1(7)

Goulielmos AM, Psifia ME (2009) Forecasting weekly freight rates for one-year time charter 65,000 DWT bulk carrier, 19892008, using nonlinear methods. Marit Policy Manag 36(5):411-436

Goulielmos AM, Psifia ME (2011) Forecasting short-term freight rate cycles: do we have a more appropriate method than a normal distribution? Marit Policy Manag 38(6):645-672

Goulielmos AM, Siropoulou E (2006) Determining the duration of cycles in the market of second-hand tanker ships, 19762001: is prediction possible? Int J Bifurcation Chaos 16(7):2119-2127 
Hale C, Vanags A (1992) The market for second-hand ships: some results on efficiency using cointegration. Marit Policy Manag 19:31-39

Hampton MJ (1991) Long and short shipping cycles. Cambridge Academy of Transport, Cambridge

Harvey AC (1990) The econometric analysis of time series. MIT Press, Cambridge

Holt CC (1957) Forecasting seasonal and trends by exponentially weighted moving averages. Carnegie Institute of Technology, Pittsburgh

Kaastra I, Boyd M (1996) Designing a neural network for forecasting financial and economic time series. Neurocomputing 10: $215-236$

Karamperidis S, Jackson E, Mangan J (2013) The use of indices in the maritime transport sector. Marit Policy Manag 40(4):339350

Kavussanos MG (1996) Comparison of volatility in the dry-cargo ship sector. J Transport Econ Policy 29:67-82

Kavussanos MG (1997) The dynamics of time-varying volatilities in different size second-hand ship prices of the dry-cargo sector. Appl Econ 29:433-444

Ko BW (2013) Analysis of term structure in dry bulk freight market. Asian J Shipping Logistics 29(1):1-22

Malkiel B (1981) A random walk down Wall street, second edition. WW Norton \& Company, Norton

Manzanero LDA, Krupp KJ (2009) Forecasting container freight rates. Copenhagen Business School Master's Thesis. Defended at the MSc in Finance and Strategic Management, Graduate Programme at CBS, Copenhagen, Denmark. Available at https://research.cbs.dk/en/studentProjects/10e340e2-b63a-4ba4-b978-0ab77227092f.

Metaxas B (1971) The economics of tramp shipping. Athlone Press, London

Murphy JJ (1986) Technical analysis of the future markets. New York Institute of Finance, New York

Ndikom O (2006) The concept of freight rates and forecasting strategy. J Res Natl Dev 4(1):8-25

Neely C, Weller P, Dittmar R (1997) Is technical analysis in the foreign exchange market profitability? A genetic programming approach. J Financ Quantit Anal 32(4):405-426

Neftci SN (1991) Naïve trading rules in finance markets and wiener-Kolmogrov prediction theory: a study of "technical analysis". J Bus 64(4):549-571

Port News, Baltic Dry Index Down to 735 points (News Report), http://en.portnews.ru/news/233851. Date of Access: 07 Feb 2017.

Pring MJ (1980) Technical analysis explained. McGraw-Hill, New York

Pring MJ (1991) Technical analysis explained, 2nd edn. McGraw-Hill, New York

Randers J, Goluke U (2007) Forecasting turning points in shipping freight rates: lessons from 30 years of practical effort. Syst Dyn Rev 23(2):253-284

Roberts HV (1959) Stock market "patterns" and financial analysis: methodological suggestions. J Financ 14(1):1-10

Sanders NR (1992) Accuracy of judgmental forecasts: a comparison. Omega Int J Manag Sci 20:353-364

Shiller RJ (1989) Investor behavior in the October 1987 stock market crash: survey evidence. Market volatility. MIT Press, Cambridge

Shimojo T (1979) Economic analysis of shipping freights. Kobe University Press, Kobe

Stopford M (2009) Maritime Economics 3e. Routledge, Abingdon, Oxon

Taylor MP, Allen H (1992) The use of technical analysis in the foreign exchange market. J Int Money Financ 11(3):304-314

The Economic Times, Definition of 'Baltic Freight Index' (News Report), Date of Access: 08 Feb 2017. http://economictimes. indiatimes.com/definition/baltic-freight-index

Tinbergen J (1959) Tonnage and freight. In: Klassen LH et al (eds) Jan Tinbergen Selected Papers. North-Holland Publishing Company, Amsterdam

Trkman P, McCormack K, Valadares de Oliveira MP, Ladeira MB (2010) The impact of business analytics on supply chain performance. Decis Support Syst 49:318-327

Tsioumas V, Papadimitriou S, Smirlis Y, Zahran SZ (2017) A novel approach to forecasting the bulk freight market. Asian J Shipping Logistics 33(1):33-41

Tversky A, Kahneman D (1992) Advances in Prospect theory: cumulative representation of uncertainty. J Risk Uncertain 5(4): 297-323

Winters PR (1960) Forecasting sales by exponentially weighted moving averages. Manag Sci 6:324-342

World Bank (2017). World Gross Domestic Product, Date of Access 24 Jan 17. http://www.worldbank.org

Xu JJ, Yip TL, Liu L (2011) A directional relationship between freight and newbuilding markets: a panel analysis. Marit Econ Logistics 13(1):44-60

Zeng Q, Qu C, Ng AK, Zhao X (2016) A new approach for Baltic dry index forecasting based on empirical mode decomposition and neural networks. Marit Econ Logistics 18(2):192-210

\section{Publisher's Note}

Springer Nature remains neutral with regard to jurisdictional claims in published maps and institutional affiliations. 